Artikel Penelitian

\title{
Faktor yang berhubungan dengan kejadian Ascariasis pada murid SD 27 Olo Kota Padang
}

\author{
Selvi Dina Safitri ${ }^{1}$, Eka Nofita $^{2}$, Dian Pertiwi ${ }^{3}$
}

\section{Abstrak}

Penyakit infeksi kecacingan, khususnya Ascariasis masih merupakan salah satu masalah kesehatan bagi penduduk Indonesia. Prevalensi Ascariasis masih cukup tinggi di Padang, Sumatra Barat, terutama pada anak usia sekolah dasar. Tujuan penelitian ini adalah menentukan faktor yang berhubungan dengan kejadian ascariasis pada murid SD 27 Olo Kota Padang. Penelitian ini menggunakan studi analitik cross sectional pada 59 murid SD 27 Olo Kota Padang dari Februari 2016-Januari 2017. Faktor yang diteliti adalah tingkat pengetahuan ibu, higienitas perorangan, sanitasi lingkungan rumah, dan tingkat penghasilan orangtua. Hubungan antara variabel dianalisis menggunakan uji chi-square. Hasil penelitian menunjukkan bahwa 20,3\% murid positif menderita ascariasis. Kejadian ascariasis lebih banyak ditemukan pada tingkat pengetahuan ibu yang cukup (21,9\%), higienitas perorangan yang baik $(20,8 \%)$, sanitasi lingkungan yang cukup $(33,3 \%)$ dan tingkat penghasilan orangtua yang rendah $(20,9 \%)$. Analisis statistik menunjukkan bahwa terdapat hubungan yang bermakna antara sanitasi lingkungan dengan kejadian ascariasis. Tingkat pengetahuan ibu, higiene perorangan dan tingkat penghasilan orangtua tidak menunjukkan hubungan yang bermakna dengan kejadian ascariasis.

Kata kunci: ascariasis, higienitas perorangan, tingkat pengetahuan ibu, sanitasi lingkungan, penghasilan orangtua

\begin{abstract}
Worm infection disease, especially Ascariasis is still one of health problem in Indonesia. Prevalence of Ascariasis is still high in Padang, West Sumatra, especially at primary school age children. The objective of this study was to determine the factors associated on the incidence of Ascariasis in SD 27 Olo Kota Padang. This study used an analytical design method of cross sectional study on 59 students in SD 27 Olo Kota Padang in February 2016-January 2017. Factors that were concerned in this study are level of maternal knowledge, personal hygiene, sanitary living environment, and the level of parental income. The relationship between all variables were analyzed by chi-square test. The results showed that $20,3 \%$ students were positive of ascariasis. The incidence of ascariasis is more common in medium-level of maternal knowledge (21,9\%), individual with good hygiene (20,8\%), medium-level of environmental sanitation (33,3\%) and low-level of parental income (20,9\%). Statistical analysis showed that there was a significant relationship between environmental sanitation and ascariasis. Maternal knowledge, personal hygiene, and parental income did not show significant correlation with the incidence of ascariasis.
\end{abstract}

Keywords: ascariasis, personal hygiene, maternal knowledge, environmental sanitation, parental income

Affiliasi penulis: 1. Prodi Profesi Dokter FK unand (Fakultas Kedokteran Universitas Andalas Padang), 2. Bagian Parasitologi FK UNAND, 3. Bagian Patologi Klinik FK UNAND

Korespondensi: Selvi Dina Safitri, Email: selvidinasafitri@yahoo.co.id Telp: 081371203013

\section{PENDAHULUAN}

Indonesia masih menghadapi masalah tingginya prevalensi penyakit infeksi, terutama yang berkaitan dengan kondisi sanitasi lingkungan yang belum baik. Salah satu penyakit yang insidennya masih tinggi adalah infeksi kecacingan. ${ }^{1}$

Penyakit kecacingan yang paling sering ditemukan adalah penyakit infeksi cacing usus yang ditularkan melalui tanah (Soil transmitted helminth atau STH). Tingginya angka kejadian Ascariasis terutama disebabkan oleh banyaknya telur yang dapat 
dihasilkan seekor cacing betina $A$. lumbricoides sebanyak 100.000-200.000 butir disertai daya tahan telur cacing pada keadaan tanah yang kondusif. Parasit ini lebih banyak ditemukan pada tanah liat dengan kelembaban tinggi dan suhu $25-30^{\circ} \mathrm{C}$ sehingga sangat baik untuk menunjang perkembangan telur cacing tersebut Prevalensi tertinggi tetap didapatkan pada golongan anak usia sekolah dasar yang berusia 5-9 tahun dikarenakan terdapat hubungan dengan kebiasaan anak-anak yang sering bermain di tanah yang terkontaminasi telur cacing sehingga lebih mudah terinfeksi. ${ }^{2,3,4,5,6}$

Penelitian yang dilakukan Ariska (2011) di SDN 201/IV Kelurahan Simpang IV Sipin Kota Jambi Tahun 2011 didapatkan hubungan antara kejadian ascariasis dengan hygiene perorangan, pengetahuan ibu dan sanitasi lingkungan ${ }^{7}$. Penelitian yang dilakukan Sandy dan Irmanto (2014) di Papua didapatkan factor risiko yang mempengaruhi infeksi ascariasis adalah hygiene perorangan (kebiasaan mencuci tangan sebelum makan dan sesudah buang air besar) dan sanitasi lingkungan (jenis lantai rumah). ${ }^{8}$

Berdasarkan penelitian yang dilakukan Khairul (2015) pada SD 27 Olo didapatkan persentase murid yang positif terinfeksi STH sebesar $47,6 \%$ dengan infeksi tunggal Ascaris lumbricoides sebesar 36,70\%, infeksi ganda Ascaris lumbricoides dan Trichuris trichiura sebesar 56,70\%, infeksi campuran Ascaris lumbricoides, Trichuris trichiura dan cacing tambang sebesar $3,3 \%$ dan infeksi tunggal Trichuris trichiura sebesar 3,3\%. Berdasarkan latar belakang di atas, peneliti tertarik untuk melakukan penelitian faktor yang berhubungan dengan kejadian Ascariasis pada murid SD 27 Olo Kota Padang.

\section{METODE}

Penelitian dilakukan terhadap siswa SD 27 Olo dari Februari 2016 sampai Januari 2017. Subjek dalam penelitian didapatkan sebanyak 59 dari semua siswa yang memenuhi kriteria inklusi dan eksklusi. Instrumen penelitian yang digunakan adalah kuesioner dan pemeriksaan tinja di Laboratorium Parasitologi. Data yang diperoleh diuji secara komputerisasi dengan uji chi-square pada $p<0,05$.
Hasil

Karakteristik Subjek Penelitian

Jenis kelamin laki-laki lebih banyak dibandingkan perempuan yaitu sebesar $50,8 \%$. Pekerjaan dari orangtua responden pada ayah yang terbanyak sebagai buruh sebesar $37,3 \%$ sedangkan pada ibu sebagai ibu rumah tangga (IRT) sebesar $84,7 \%$. Pendidikan orangtua responden lebih banyak yang memiliki pendidikan terakhir SMA dimana pada ayah didapatkan sebesar $61 \%$ dan pada ibu sebesar $59,3 \%$.

Kejadian Ascariasis, Pengetahuan Ibu, Higienitas Perorangan, Sanitasi Lingkungan, dan Penghasilan Orangtua

Tabel 1 menunjukkan bahwa jumlah murid yang menderita ascariasis berjumlah 12 orang $(20,3 \%)$. Sebagian besar ibu memiliki pengetahuan yang cukup mengenai penyakit kecacingan (54,2\%). Sebagian besar murid memiliki higienitas perorangan yang baik $(81,4 \%)$. Sebagian besar murid memiliki sanitasi lingkungan yang cukup (50,8\%). Sebagian besar orang tua memiliki penghasilan yang rendah (72,9\%).

Tabel 1. Hasil analisis univariat terhadap variabel yang diteliti pada murid SD 27 Olo Kota Padang

\begin{tabular}{ccc}
\hline & $\mathbf{f}$ & $\%$ \\
\hline KejadianAscariasis & 12 & $20,3 \%$ \\
- Positif & 47 & $79,7 \%$ \\
- Negatif & & \\
Pengetahuanlbu & 2 & $3,4 \%$ \\
- Kurang & 32 & $54,2 \%$ \\
- Cukup & 25 & $42,4 \%$ \\
- Baik & & \\
HigienePeroranganAnak & 0 & $0 \%$ \\
- Kurang & 11 & $18,6 \%$ \\
- Cukup & 48 & $81,4 \%$ \\
- Baik & & \\
SanitasiLingkungan & 0 & $0 \%$ \\
- Kurang & 30 & $50,8 \%$ \\
- Cukup & 29 & $49,2 \%$ \\
- Baik & & \\
PenghasilanOrangtua & 43 & $72,9 \%$ \\
- Rendah & 16 & $27,1 \%$ \\
\hline$\quad$ Tinggi & & \\
\hline
\end{tabular}


Hubungan Pengetahuan lbu dengan Kejadian

Ascariasis

Tabel 2. Hubungan pengetahuan ibu dengan kejadian ascariasis pada murid SD 27 Olo Kota Padang

\begin{tabular}{|c|c|c|c|c|c|}
\hline \multirow{3}{*}{ Pengetahuan Ibu } & \multicolumn{4}{|c|}{ KejadianAscariasis } & \multirow{3}{*}{$\mathbf{p}$} \\
\hline & \multicolumn{2}{|c|}{ Positif } & \multicolumn{2}{|c|}{ Negatif } & \\
\hline & $f$ & $\%$ & $\mathbf{f}$ & $\%$ & \\
\hline Kurang + & 7 & 20,6 & 27 & 79,4 & 1,000 \\
\hline \multicolumn{6}{|l|}{ Cukup } \\
\hline Baik & 5 & 20 & 20 & 80 & \\
\hline Total & 12 & 20,3 & 47 & 79,7 & \\
\hline
\end{tabular}

Berdasarkan uji statistik pada Tabel 2, antara pengetahuan ibu dan kejadian ascariasis didapatkan hasil $p=1,000 \quad(p>0,05)$, dengan demikian tidak terdapat hubungan yang bermakna antara pengetahuan ibu dengan kejadian ascariasis pada murid SD 27 Olo Kota Padang.

\section{Hubungan Higiene Perorangan dengan Kejadian}

\section{Ascariasis}

Tabel 3. Hubungan higiene perorangan dengan kejadian ascariasis pada murid SD 27 Olo Kota Padang

\begin{tabular}{lccccc}
\hline \multirow{2}{*}{ Higiene perorangan } & \multicolumn{4}{c}{ KejadianAscariasis } & \multirow{2}{*}{$\mathbf{p}$} \\
\cline { 2 - 4 } & \multicolumn{2}{c}{ Positif } & \multicolumn{2}{c}{ Negatif } & \\
\cline { 2 - 5 } & $\mathbf{f}$ & $\%$ & $\mathbf{f}$ & $\%$ & \\
\hline Kurang + & 2 & 16,7 & 9 & 19,1 & 1,000 \\
Cukup & & & & & \\
Baik & 10 & 83,3 & 38 & 80,9 & \\
\hline Total & 12 & 100 & 47 & 100
\end{tabular}

Pada Tabel 3 terlihat bahwa antara higiene perorangan dan kejadian ascariasis didapatkan hasil $p=1,000 \quad(p>0,05)$, dengan demikian tidak terdapat hubungan yang bermakna antara higiene perorangan dengan kejadian ascariasis pada murid SD 27 Olo Kota Padang.

\section{Hubungan Sanitasi Lingkungan dengan Kejadian}

Ascariasis

Tabel 4 memperlihatkan hubungan antara sanitasi lingkungan dengan kejadian ascariasis didapatkan hasil $p=0,028(p<0,05)$, dengan demikian terdapat hubungan yang bermakna antara sanitasi lingkungan dengan kejadian ascariasis.
Tabel 4. Hubungan sanitasi lingkungan dengan kejadian ascariasis pada murid SD 27 Olo Kota Padang

\begin{tabular}{|c|c|c|c|c|c|}
\hline \multirow{3}{*}{ Sanitasi lingkungan } & \multicolumn{4}{|c|}{ KejadianAscariasis } & \multirow{3}{*}{$\mathbf{p}$} \\
\hline & \multicolumn{2}{|c|}{ Positif } & \multicolumn{2}{|c|}{ Negatif } & \\
\hline & $f$ & $\%$ & $f$ & $\%$ & \\
\hline Kurang + & 10 & 33,3 & 20 & 66,7 & 0,028 \\
\hline \multicolumn{6}{|l|}{ Cukup } \\
\hline Baik & 2 & 6,9 & 27 & 93,1 & \\
\hline Total & 12 & 20,3 & 47 & 79,7 & \\
\hline
\end{tabular}

Hubungan Penghasilan Orangtua dengan Kejadian Ascariasis

Tabel 5. Hubungan penghasilan orangtua dengan kejadian ascariasis pada murid SD 27 Olo Kota Padang

\begin{tabular}{lccccc}
\hline \multirow{2}{*}{ Penghasilan orangtua } & \multicolumn{4}{c}{ KejadianAscariasis } & \multirow{2}{*}{$\mathbf{p}$} \\
\cline { 2 - 4 } & Positif & \multicolumn{2}{c}{ Negatif } & \\
\cline { 2 - 4 } & $\mathbf{f}$ & $\%$ & $\mathbf{f}$ & $\%$ & \\
\hline Rendah & 9 & 20,9 & 34 & 79,1 & 1,000 \\
Tinggi & 3 & 18,8 & 13 & 81,3 & \\
\hline Total & 12 & 20,3 & 47 & 79,7 & \\
\hline
\end{tabular}

Berdasarkan uji statistik pada Tabel 5, antara penghasilan orangtua dengan kejadian ascariasis didapatkan hasil $p=1,000$ ( $p>0,05)$, dengan demikian tidak terdapat hubungan yang bermakna antara penghasilan orangtua dengan kejadian ascariasis pada murid SD 27 Olo Kota Padang.

\section{PEMBAHASAN}

\section{Kejadian Ascariasis}

Prevalensi murid SD 27 Olo Kota Padang yang menderita ascariasis didapatkan sebesar $20,3 \%$. Hasil penelitian ini lebih rendah dibandingkan dengan penelitian yang dilakukan Khairul di sekolah yang sama pada tahun 2015 sebesar $96,7 \%{ }^{9}$

Prevalensi ini berbeda dengan yang dilakukan Fulanda (2015) di SD 14 Olo Kota Padang yang mendapatkan prevalensi Ascariasis sebesar 36,5\%. ${ }^{10}$ Penelitian Marvinza (2015) di SDN 02 Ulakan Tapakis Kabupaten Padang Pariaman mendapatkan prevalensi ascariasis sebesar 30,6\%. ${ }^{11}$ Penelitian Asrytuti (2016) pada SD Negeri 23 Pasir Sebelah mendapatkan prevalensi Ascariasis sebesar 26,2\%. ${ }^{12}$ 
Tingginya prevalensi infeksi ascariasis dapat disebabkan oleh berbagai faktor seperti angka sosioekonomi yang rendah, pendidikan yang rendah, kesadaran kebersihan yang rendah, perilaku hidup bersih dan sehat (PHBS) yang rendah, serta pengetahuan tentang kesehatan yang kurang.

Hasil penelitian pada murid SD 27 Olo menunjukkan penurunan kejadian ascariasis dibandingkan tahun sebelumnya. penurunan kejadian ascariasis menunjukkan bahwa terjadi penurunan faktor risiko yang menyebabkan berkurangnya rantai penularan dari infeksi $A$. lumbricoides. Hal ini terlihat dari sebagian besar orangtua murid yang tingkat pengetahuannya sedang tentang penyakit kecacingan $(54,2 \%)$, sebagian besar murid memiliki higienitas perorangan yang baik $(81,4 \%)$ dan sanitasi lingkungan yang sedang $(50,8 \%)$.

\section{Pengetahuan Ibu}

Berdasarkan penelitian mengenai tingkat pengetahuan ibu tentang penyakit kecacingan khususnya ascariasis didapatkan bahwa murid yang positif menderita ascariasis lebih banyak pada ibu yang tingkat pengetahuannya kurang sampai cukup (20,6\%) diikuti ibu yang tingkat pengetahuannya baik $(20 \%)$. Berdasarkan uji statistik tidak terdapat hubungan antara tingkat pengetahuan ibu dengan kejadian ascariasis pada murid SD 27 Olo Kota Padang.

Hasil penelitian ini didukung oleh penelitian Ihsan (2014) pada murid SD 25 dan 28 Purus dimana tidak ditemukan hubungan yang bermakna antara tingkat pengetahuan ibu dengan kejadian Ascariasis ${ }^{13}$. Berbeda dengan hasil penelitian yang dilakukan Ariska (2011) pada murid SDN 201/IV Kelurahan Simpang IV Sipin di Kota Jambi dimana didapatkan hubungan yang bermakna antara kedua variabel tersebut ${ }^{7}$.

Peran orang tua, terutama seorang ibu merupakan model atas tingkah laku social bagi sang anak, juga dalam berperilaku sehat khususnya dalam pencegahan penyakit kecacingan. Wanita sebagai ibu rumahtangga merupakan penentu utama, sebagai pengasuh dan pendidik anak dalam upaya meningkatkan kesehatan lingkungan dan pribadi. Meningkatnya kesadaran akan kesehatan lingkungan dan pribadi diharapkan akan memotong rantai penularan penyakit cacing usus pada anak-anak usia sekolah. Peran ibu dapat memperkecil terjadinya reinfeksi penyakit cacing pada anak. ${ }^{14}$

\section{Higienitas Perorangan}

Berdasarkan penelitian terhadap higienitas perorangan murid SD 27 Olo kota Padang didapatkan bahwa murid yang positif menderita Ascariasis lebih banyak memiliki higienitas perorangan yang baik $(20,8 \%)$ dan sedikit pada murid yang memiliki higienitas perorangan yang kurang sampai cukup $(18,2 \%)$

Berdasarkan uji statistik tidak terdapat hubungan antara higienitas perorangan dengan kejadian Ascariasis pada murid SD 27 Olo Kota Padang. Hasil penelitian ini sama dengan hasil penelitian yang dilakukan oleh Ihsan (2014) dimana tidak terdapat hubungan antara higienitas perorangan dengan kejadian Ascariasis $^{13}$. Lain halnya dengan hasil penelitian yang dilakukan Ariska (2011) dimana terdapat hubungan antara higienitas perorangan dengan kejadian Ascariasis Higiene yang baik merupakan syarat penting dalam mencegah dan memutuskan mata rantai penyebaran penyakit menular seperti kecacingan ${ }^{7,15}$

Pada murid SD 27 Olo, sebagian besar memiliki higienitas perorangan yang baik. Banyaknya murid yang memiliki higienitas perorangan yang baik mungkin disebabkan karena di daerah penelitian yaitu Olo Ladang, Kota Padang, sebagian besar masyarakat telah membuang air besar di WC/jamban, lalu kebiasaan menggunakan alas kaki saat bermain sudah banyak dilakukan oleh murid-murid SD 27 Olo. Adanya peran dari orangtua yang mendidik anak untuk menjaga kebersihan akan berpengaruh terhadap perilaku anak untuk menjaga kebersihan pribadi.

\section{Sanitasi Lingkungan}

Hasil penelitian menunjukkan ternyata kejadian ascariasis pada murid SD 27 Olo Kota Padang lebih banyak pada murid dengan sanitasi lingkungannya yang kurang sampai cukup $(33,3 \%)$ dan sedikit pada murid dengan sanitasi lingkungan yang baik (6,9\%). 
Berdasarkan uji statistik terdapat hubungan yang bermakna antara sanitasi lingkungan dengan kejadian ascariasis pada murid SD 27 Olo Kota Padang. Hasil penelitian ini didukung oleh penelitian Ariska (2011) dimana terdapat hubungan yang bermakna antara sanitasi lingkungan dengan kejadian Ascariasis pada murid SD di Jambi. ${ }^{7}$ Berbeda dengan penelitian Ihsan (2014) di Kota Padang yang menyatakan tidak terdapat hubungan antara kedua variabel tersebut. ${ }^{13}$

Infeksi tidak langsung dapat terjadi apabila telur yang infektif melekat pada badan atau kaki lalat dari tinja manusia yang terdapat di tanah dan sudah mengandung telur matang, karena lalat dan kecoa secara tidak langsung akan mencemari makanan yang dihidangkan di meja yang tidak ditutup dengan tudung penutup makanan. Lalat dan kecoa biasanya mendatangi rumah-rumah yang terletak di sekitar perindukannya. $^{16}$

Kejadian Ascariasis banyak ditemukan pada murid dengan sanitasi lingkungan yang sedang dan baik. Observasi yang dilakukan di lapangan banyak ditemukan makanan yang tidak ditutup dengan tudung saji pada rumah yang anaknya terinfeksi Ascariasis. Selain itu, rumah yang ditinggali tidak memiliki jamban dan kamar mandi sendiri sehingga kegiatan mandi dan buang air kecil/buang air besar dilakukan di luar rumah (kamar mandi dan jamban dipakai bersama). Padahal untuk mencegah sekurang-kurangnya kontaminasi tinja terhadap lingkungan maka pembuangan kotoran manusia harus dikelola dengan baik.

\section{Penghasilan Orangtua}

Hasil penelitian menunjukkan bahwa murid yang positif ascariasis lebih banyak pada orangtua dengan tingkat penghasilan yang rendah $(20,9 \%)$ dibandingkan orangtua dengan tingkat penghasilan yang tinggi (18,8\%). Berdasarkan uji statistik tidak terdapat hubungan yang bermakna antara tingkat penghasilan orangtua murid dengan kejadian Ascariasis pada murid SD 27 Olo Kota Padang. Hasil penelitian ini sama dengan penelitian Ihsan (2011) yaitu tidak ada hubungan antara kejadian Ascariasis dengan tingkat penghasilan orang tua murid ${ }^{13}$.
Berbeda dengan penelitian Pebrisa (2008) dimana ditemukan hubungan yang bermakna antara kejadian Ascariasis dengan penghasilan orangtua murid. ${ }^{17}$

Salah satu faktor yang mempengaruhi kejadian infeksi, termasuk kejadian ascariasis pada murid sekolah dasar adalah tingkat penghasilan orang tua yang rendah. $^{18}$ Tingkat penghasilan yang rendah, maka upaya untuk pemenuhan kebutuhan primer seperti sandang, pangan dan papan akan lebih diutamakan dibandingkan pemenuhan kebutuhan sekunder seperti kesehatan. Masyarakat dengan tingkat penghasilan yang rendah tidak akan memikirkan kesehatan pribadi maupun keluarga sebelum jatuh sakit. Orangtua murid dengan tingkat penghasilan yang rendah akan mempengaruhi status gizi anak mereka Banyaknya orangtua murid yang berpenghasilan rendah dapat disebabkan karena sebagian besar pekerjaan orangtua terutama ayah murid SD 27 Olo Kota Padang adalah buruh, sehingga penghasilan mereka kebanyakan di bawah nilai Upah Minimun Provinsi (UMP) Sumatera Barat tahun 2016 yaituRp. $1.800 .725^{19,20}$

\section{SIMPULAN}

Tidak terdapat hubungan yang bermakna antara kejadian ascariasis dengan pengetahuan orangtua murid SD 27 Olo Kota Padang.

Tidak terdapat hubungan yang bermakna antara kejadian ascariasis dengan hygiene perorangan murid SD 27 Olo Kota Padang.

Terdapat hubungan yang bermakna antara sanitasi lingkungan dengan kejadian ascariasis pada murid SD 27 Olo Kota Padang.

Tidak terdapat hubungan yang bermakna antara kejadian ascariasis dengan tingkat penghasilan orangtua murid SD 27 Olo Kota Padang.

\section{DAFTAR PUSTAKA}

1. Hairani B, Annida. Insidensi parasit pencernaan pada anak sekolah dasar di perkotaan dan pedesaan di kabupaten Tanah Bumbu Kalimantan Selatan. Jurnal Buski. 2012;4(2):102-8. 
2. Anwar RY. Hubungan antara higiene perorangan dan infeksi cacing usus pada siswa Sekolah Dasar Negeri 25 dan 28 di Kelurahan Purus Kota Padang Sumatera Barat (skripsi). Padang: Universitas Andalas; 2013.

3. Natadisastra D, Agoes D. Parasitologi kedokteran ditinjau dari organ tubuh yang diserang. Jakarta: EGC; 2009.

4. Sutanto I, Ismid IS, Sjarifudin PK, Sungkar S. Buku ajar parasitologi kedokteran. Edisi ke-4. Jakarta: Balai Penerbit FKUI; 2008.

5. Hotez PJ, Molyneux DH, Fenwick A, Kumaresan J, Sachs SE, Sachs JD, et al. Control of neglected tropical diseases. The New England Journal of Medicine. 2007;357(10):1018-27.

6. Manganelli L, Berrilli F, Di Cave D, Ercoli L, Capelli $\mathrm{G}$, Otranto $\mathrm{D}$, et al. Intestinal parasite infections in immigrant children in the city of Rome, related risk factors and possible impact on nutritional status. Parasites \& Vectors. 2012;5(265):1-5.

7. Ariska BM. Beberapa faktor yang berhubungan dengan kejadian infeksi cacing Ascaris lumbricoides pada murid SDN 201/IV di Kelurahan Simpang IV Sipin Kota Jambi (skripsi). Padang: Universitas Andalas; 2011.

8. Sandy S, Irmanto M. Analisis model faktor risiko infeksi cacing gelang (Ascaris lumbricoides) pada murid SD di Distrik Arso Kabupaten Keerom Papua. Jurnal Buski. 2014;5(1):35-42.

9. Khairul IA. Hubungan infeksi soil transmitted helminth dengan status gizi murid kelas I-IV SDN 27 Olo Padang (skripsi). Padang: Universitas Andalas; 2015.

10. Fullanda A. Frekuensi Ascaris lumbricoides pada murid SDN 14 Olo Ladang Padang (skripsi).Padang: Universitas Andalas; 2015.

11. Marvinza R. Hubungan infeksi soil-transmitted helminth dengan status gizimurid SDN 02 UlakanTapakisKabupaten Padang Pariaman (Skripsi S1). Padang: Universitas Andalas; 2015.
12. Asrytuti V. Hubungan hygiene perorangan dengan askariasis padasiswa SD Negeri 23 Pasir Sebelah Kecamatan Koto Tangah Padang (skripsi). Padang: Universitas Andalas; 2016.

13. Ihsan AM. Faktor-faktor yang berhubungan dengan kejadian ascariasis pada murid SDN 25 dan 28 Purus, Kota Padang tahun 2013 (skripsi). Padang: Universitas Andalas; 2014.

14. Astuti D, Supardi S, Sumarni S. Peranan pendidikan kesehatan pada ibu terhadap reinfeksi penyakit cacing pada anak usia sekolah dasar. Sains Kesehatan. 2002;15(2):145-53.

15. Martila, Sandy S, Paembonan N. Hubungan hygiene perorangan dengan kejadian kecacingan pada murid SD Negeri Abe PantaiJayapura. Plasma Jurnal Kesehatan. 2015;1(2):87-96.

16. Helmy D, Herryanto, Inswiasri. Penyakit cacing di unit permukiman transmigrasi Propinsi Bengkulu pada anak sekolah dasar. Media Litbang Kesehatan. 2000;10(2):32-6.

17. Pebrisa D. Faktor-faktor yang berhubungan dengan kejadian kecacingan pada murid SDN 30 Air Dingin Kecamatan Koto Tangah Kota Padang Tahun 2008 (skripsi). Padang: Universitas Andalas; 2008.

18. Ginting A. Faktor-faktor yang berhubungan dengan kejadian kecacingan pada anak sekolah dasar di desa tertinggal Kecamatan Poungururan Kabupaten Samosir (skripsi). Medan: Universitas Sumatera Utara; 2008.

19. Krevani CK. Hubungan infeksi Ascaris lumbricoides dengan status gizi murid kelas I dan II SDN 23 Pasir Sebelah Kecamatan Koto Tangah Kota Padang (skripsi). Padang: Universitas Andalas; 2004.

20. Pemerintah Provinsi Sumatera Barat. Upah Minimum Provinsi (UMP) di Provinsi Sumatera Barat tahun 2010-2016. (diunduh 26 Juli 2016). Tersedia dari: URL: HYPERLINK http://www.sumbarprov.go.id/details/news/6489 